\title{
Estimation of Forest Area and Canopy Cover Based on Visual Interpretation of Satellite Images in Ethiopia
}

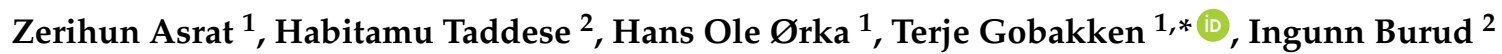 \\ and Erik Næsset ${ }^{1}$ \\ 1 Faculty of Environmental Sciences and Natural Resource Management, Norwegian University of Life \\ Sciences, P.O. Box 5003, 1432 Ås, Norway; zerihun.asrat.kutie@nmbu.no (Z.A.); \\ hans.ole.orka@nmbu.no (H.O.Ø.); erik.naesset@nmbu.no (E.N.) \\ 2 Faculty of Science and Technology, Norwegian University of Life Sciences, P.O. Box 5003, 1432 Ås, Norway; \\ habitamu.taddese.berie@nmbu.no (H.T.); ingunn.burud@nmbu.no (I.B.) \\ * Correspondence: terje.gobakken@nmbu.no; Tel.: +47-67-23-17-55
}

Received: 23 May 2018; Accepted: 24 July 2018; Published: 30 July 2018

\begin{abstract}
Forests, particularly in the tropics, are suffering from deforestation and forest degradations. The estimation of forest area and canopy cover is an essential part of the establishment of a measurement, reporting, and verification (MRV) system that is needed for monitoring carbon stocks and the associated greenhouse gas emissions and removals. Information about forest area and canopy cover might be obtained by visual image interpretation as an alternative to expensive fieldwork. The objectives of this study were to evaluate different types of satellite images for forest area and canopy cover estimation though visual image interpretation, and assess the influence of sample sizes on the estimates. Seven sites in Ethiopia with different vegetation systems were subjectively identified, and visual interpretations were carried out in a systematical design. Bootstrapping was applied to evaluate the effects of sample sizes. The results showed that high-resolution satellite images $(\leq 5 \mathrm{~m})$ (PlanetScope and RapidEye) images produced very similar estimates, while coarser resolution imagery $(10 \mathrm{~m}$, Sentinel-2) estimates were dependent on forest conditions. Estimates based on Sentinel-2 images varied significantly from the two other types of images in sites with denser forest cover. The estimates from PlanetScope and RapidEye were less sensitive to changes in sample size.
\end{abstract}

Keywords: land cover; land use; visual interpretation; high resolution imagery; estimation; design-based inference

\section{Introduction}

Forests constitute the largest terrestrial ecosystem, and they provide a variety of services and functions [1,2]. One of the services that forests offer is carbon sequestration; approximately 2.5 billion tons carbon are absorbed annually [3-5]. Despite their contributions to carbon sequestration, much of the world's forests, particularly tropical forests, are suffering from severe deforestation and degradation, contributing to increased carbon emission [5-7]. About $12 \%$ of the total anthropogenic carbon emissions come from deforestation $[5,8]$. The pressure from deforestation and degradation on forests is larger particularly in tropical, developing countries due to heavy dependence on the resource for livelihoods [9].

The world has been acting continuously from the Kyoto Protocol in 1992 to the recent Paris Agreement in 2015 to halt the global warming through various means, one of which is the REDD+ mechanism (Reducing Emissions from Deforestation and forest Degradation). The REDD+ mechanism gives financial incentives to countries decreasing their deforestation and forest degradation. Ethiopia is one of the tropical countries that has lost much of its forest resources in the past [10]. Historically, 
the forest cover of Ethiopia was reported to be more than $30-40 \%$ of the area $[10,11]$. However, the origin of this number is uncertain, and the amount itself is questionable [12]. Either way, there has been severe deforestation and forest degradation in the country the last century [11-14]. The pressure to convert forests into land for food production to support the increasing human population and provide socio-economic benefits to the nature-based livelihoods of the majority of the people has been huge. The use of wood for fuel has also aggravated the rate of deforestation $[10,11]$.

Ethiopia is currently in the process of implementing REDD+, and one of the prerequisites for implementing the REDD+ mechanism is to develop a robust measuring, reporting, and verification (MRV) system following the Intergovernmental Panel on Climate Change (IPCC) Good Practice Guidelines [15]. Information about forest area and canopy cover are required for a MRV system in the REDD+ process and sustainable forest management practices. Forest area is the proportion of an area that is covered with trees and other perennial components of a forest land. The definition of forest varies among countries, the contexts of institutions, and of course the purpose [16]. The Food and Agriculture Organization (FAO) of the United Nations defines forest as land spanning more than 0.5 hectares with trees higher than $5 \mathrm{~m}$ and a canopy cover of more than $10 \%$, or trees that are able to reach these thresholds in situ [17]. In Ethiopia, the working definition of forest describes it as any land spanning at least 0.5 hectares covered by trees (including bamboo) attaining a height of at least $2 \mathrm{~m}$ and a canopy cover of at least $20 \%$, or trees with the potential to reach these thresholds in situ in due course. Canopy cover is the proportion of the forest floor covered by the vertical projection of the tree crowns $[15,18,19]$. Canopy cover plays a significant role in forest management for various decisions related to silviculture and the utilization of the forests [20].

In REDD+, developing countries rehabilitate and preserve their forests, and in turn get paid for the extra amount of $\mathrm{CO}_{2}$ sequestered beyond a certain agreed level following MRV after their commitment [21]. The REDD+ system, of course, requires accurate measurement and estimation methods to be carried out through a properly established MRV system [22]. In the course of quantifying the amount of $\mathrm{CO}_{2}$ by sink and source, reliable forest area and canopy cover estimations are key attributes $[15,23]$. However, according to the IPCC, information on forest area and deforestation in tropical countries is highly uncertain, often up to $50 \%$ of error [24]. This is because tropical countries are constrained by a lack of technical capacity and lack of both trained human power as well as infrastructure. In such situations, when and where there are technical inefficiencies, it would be important to critically scrutinize and choose the most feasible methods and technologies [23].

Past and current practices of forest cover assessment as well as land-use and land-cover (LULC) mapping in Ethiopia, digital image classification, and mapping methods are practiced, such as supervised, unsupervised, and object-based classification (e.g., $[13,14])$. However, digital image classification and mapping methods in general require a high level of technical skill, and in most cases, technical software $[25,26]$. Furthermore, the spectral similarity of land-cover classes is also challenging. As a result, the wider application and use of such methodologies for large-scale activities such as nationwide assessment could be problematic. For instance, Ethiopia's historical data on LULC changes between 2000-2013 for forest reference level (FRL) submission to the United Nations Framework Convention on Climate Change (UNFCCC) were generated through digital image classification and mapping using Landsat data. Nevertheless, the report underlined the need for the further reduction of uncertainties of the estimates [27]. In response to the drawbacks of digital image classification and mapping mentioned above, some platforms of free and open source software such as Geo-Wiki, VIEW-IT, and Sky Truth are developed by different bodies, including academic institutions [26,28]. The software support visual satellite image interpretation and LULC map validation by non-remote sensing experts, while some of the programs can also be used for other advanced applications by professional users [26,29]. The application of these software packages is associated with the use of very high-resolution images, which are often known to have a small geographic scope and an irregular time interval of acquisition, in turn limiting its utility for large areas. On the other hand, using Landsat images will provide a global coverage with bi-monthly acquisitions; however, interpretation is limited 
by its low spatial resolution. FAO designed the software system Collect Earth as an open source tool that helps to collect, analyze, and compile reports on LULC through visual image interpretation based on freely available satellite images mainly with the Google Earth platform [25]. The tool has been adopted, and many countries have used it around the world for activities such as national forest inventory, LULC mapping, and the estimation of activity data for REDD+ [25].

The mentioned software supporting visual satellite image interpretation are efficient tools for gathering reference data. Such reference data gathered using interpretation of satellite imagery with different spatial resolutions under different forest conditions has been used to provide forest area and forest cover change estimates [30,31]. However, forest conditions and properties of the imagery, such as spatial resolution and revisit times, could potentially influence estimates. Hence, it is important to evaluate different types of satellite images under different forest conditions in order to provide guidelines for using such tools at a national level.

Thus, the aim of this study was to identify and evaluate different and alternative types of satellite images to minimize the level of uncertainties of the estimation of forest area and canopy cover in different forest conditions in Ethiopia. The specific objectives of the study were to: (1) evaluate the use of PlanetScope, RapidEye, and Sentinel-2 satellite images for forest area and canopy cover estimation through visual interpretation; and (2) assess the influence of sample sizes on the estimates. Accordingly, efforts were made to see if there is variation in the pattern of the estimates and the uncertainty of estimates from the three types of satellite images over the different areas of interest (sites of the study), which are characterized by having different biomes. Thus, such efforts would provide insight on the robustness of the method when applied to different forest conditions. The time elapsed for interpretation was assessed to evaluate the effectiveness of the method. In general, the study sites were selected so that they covered the important carbon storage areas of the country. Therefore, the study is helpful for gaining knowledge and contributing to improving Ethiopia's REDD+ MRV system in practice.

\section{Materials and Methods}

\subsection{Description of the Study Sites}

Ethiopia is located in eastern Africa, geographically extending from $3^{\circ}$ to $15^{\circ}$ north latitude and from $33^{\circ}$ to $48^{\circ}$ east longitude. It is known for its topographic diversity, stretching from the lowest Danakil depression $125 \mathrm{~m}$ below sea level to the highest peak of the Simien Mountains, which is over $4500 \mathrm{~m}$ above sea level. The great East African rift valley that runs from northeast to southwest divides the country into north, northwest, and southwest highlands and the western lowlands on one side, and the eastern and southeastern highlands and the associated lowlands on the other side [32]. This topographic diversity favored the country to have a wide range of climate and a diverse flora and fauna, with a considerable amount of it being endemic [33].

For this study, seven sites were identified to represent the major biomes of the country, as well as their tree gain or loss conditions (Table 1). The selection of sites was subjective in order to have sites covering a range of forest conditions. The size of each site was $2052 \mathrm{~km}^{2}(36 \mathrm{~km} \times 57 \mathrm{~km})$. The major biomes were used in activity data compilation for FRL submission to the UNFCCC, and stratification during the national forest inventory planning and implementation [27]. The major biomes include (1) Dry Afromontane: includes undifferentiated Afromontane forest; dry single dominant Afromontane forest of the Ethiopian highland; Afromontane woodland, wooded grassland, and grassland. In addition, transition between Afromontane vegetation and Acacia-Commiphora bushland on the eastern escarpment, as well as Ericaceous and Afroalpine belts, are included. (2) Moist Afromontane: comprises mainly primary or mature secondary moist evergreen Afromontane forest. Also contains edges of moist evergreen Afromontane forest, bushland, woodland, and wooded grassland, as well as transitional rain forest. (3) Combretum-Terminalia: Combretum-Terminalia woodland and wooded grassland is a major component. Furthermore, it includes wooded grassland of 
the western Gambela region. (4) Acacia-Commiphora: Acacia-Commiphora woodland and bushland proper; Acacia wooded grassland of the rift valley as well as desert and semi-desert vegetation [32]. Accordingly, dry Afromontane forests cover the north, central, and eastern highlands of the country; moist Afromontane forests dominate the southwest and south-central areas. Combretum-Terminalia covers the northwest, west, and southwest lowlands; Acacia-Commiphora includes the northeast, east, and south lowlands of the country, while the rest that is categorized as others included water bodies and wetlands (Figure 1).

Table 1. Description of the study sites.

\begin{tabular}{ccc}
\hline Site & Biome Type & Condition of Forest in the Area * \\
\hline A & Acacia-Commiphora and partly dry Afromontane & Both tree gain and loss of similar magnitude \\
B & Characterized by tree loss \\
C & Partly moist Afromomtane and partly Acacia-Commiphora & Characterized by tree loss and very little gain \\
D & Moist Afromontane & Characterized by tree loss \\
E & Moist Afromontane & Both tree gain and loss of similar magnitude \\
F & Dry Afromontane & Characterized by tree gain \\
G & Combretum-Terminalia & Characterized by tree loss \\
\hline
\end{tabular}

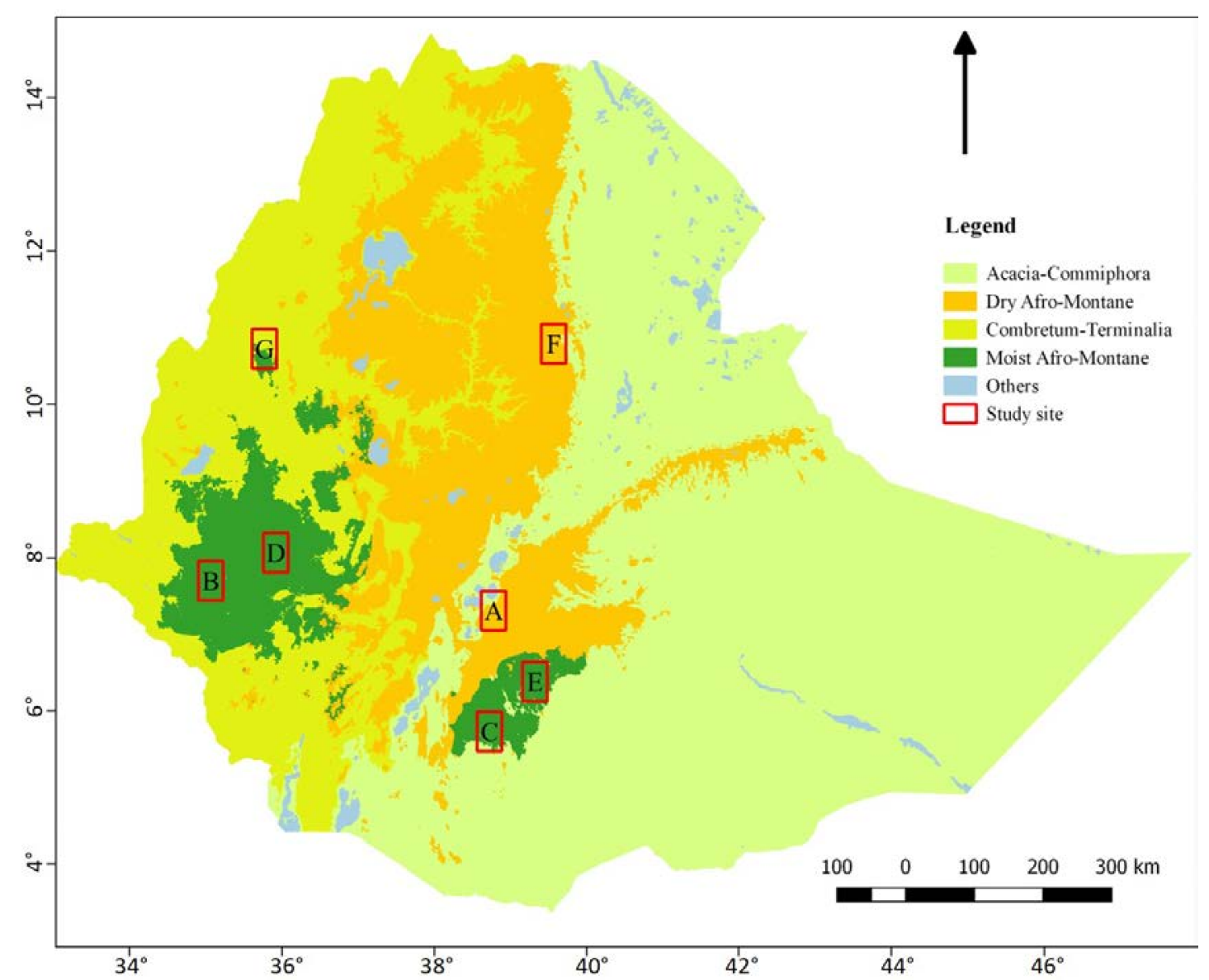

Figure 1. The major biomes in Ethiopia and the seven sites $(A, B, \ldots, G)$ selected for the study.

\subsection{Satellite Imagery}

Satellite images upon which the visual interpretation was based were PlanetScope, RapidEye, and Sentinel-2, which were all in their true color image (red, blue, and green). 


\subsubsection{PlanetScope}

PlanetScope image products are available in three different forms. PlanetScope Basic Scene (1B) is a product with radiometric and sensor corrections only, which is designed for users with advanced knowledge of image processing. PlanetScope Ortho Scene (3B) is an orthorectified product that is projected to a cartographic projection. PlanetScope Ortho Tile (3A) products are orthorectified as individual $25 \mathrm{~km} \times 25 \mathrm{~km}$ tiles, and can serve a wide range of applications that need accurate geolocation and cartographic projection. PlanetScope satellite imagery is state-of-the-art optical products with up to 3-m spatial resolution. Unlike other optical satellites, the PlanetScope satellite constellation consists of multiple launches of groups of individual satellites (also called "Doves") with continuous improvements of on-orbit capacity. The complete PlanetScope constellation of about 175 satellites (by 2 April 2018) covers the entire earth's landmass every day, and has a daily collection capacity of about 300 million $\mathrm{km}^{2}$. PlanetScope Ortho Tile images of the study sites were downloaded from the Planet Explorer Beta website in June 2017. Only images with cloud cover $<50 \%$ and images acquired between January-May 2017 were used. On average, 13.0 images were available for each location. The minimum number of images per location was four, and the maximum was 24 .

\subsubsection{RapidEye}

RapidEye and PlanetScope imagery products are currently acquired and supplied by the same private company, Planet Labs Inc. RapidEye provides optical imagery from a constellation of five earth-imaging satellites. It has a large area coverage with frequent revisit time (one-day interval), which allows one to get cloud-free images for almost all areas. The images have high spatial (5-m pixel size) resolution. RapidEye image products can be obtained in different forms (RapidEye basic (1B): least processed product; RapidEye Ortho (3A): orthorectified and other required corrections made at individual $25 \mathrm{~km} \times 25 \mathrm{~km}$ tiles; and RapidEye Ortho Take (3B): large-scale orthorectified product based on RapidEye Image Takes), depending on the users' needs and image processing capability (Planet, 2017). Recent RapidEye Ortho Take (product level 3B) images of the study sites were obtained from the same source as PlanetScope. Only images with a cloud cover $<50 \%$ and images from December 2015 to May 2017 were used. The minimum number of images per location was one, and the maximum was 12 images; on average, 4.5 RapidEye images were available for interpretation for each location.

\subsubsection{Sentinel-2}

Sentinel-2 is owned by the European Space Agency (ESA); it was launched to support activities such as land monitoring, emergency management, security, and climate change issues. In order to fulfill such objectives, the mission was designed in such a way that it has high revisit frequency (five days at the equator), high spatial resolution (up to $10 \mathrm{~m}$ in some bands), and having wider swath $(290 \mathrm{~km})$. It has been providing unprecedented freely available data to the public since June 2015 . The Sentinel-2 product level 2A images (Table 2) used for this study were also downloaded from the Planet Explorer Beta. Only images with a cloud cover $<50 \%$ and images from December 2016 to May 2017 were used. The average number of Sentinel-2 images available for interpretation at each location was 5.6 with a range from two to 10 images.

Table 2. Satellite images used in this study.

\begin{tabular}{ccc}
\hline Satellite & Spatial Resolution $(\mathbf{m})$ & Product Level \\
\hline Planet Scope & 3 & $3 \mathrm{~B}$ \\
RapidEye & 5 & $3 \mathrm{~B}$ \\
Sentinel-2 & 10 & $2 \mathrm{~A}$ \\
\hline
\end{tabular}




\subsection{Data Collection Techniques}

For each of the seven sites, a $3 \mathrm{~km} \times 3 \mathrm{~km}$ grid of systematically distributed points were prepared and overlaid the images. This resulted in 228 sample points within each site. Systematic sampling design was used because of its potential to uniformly cover the entire sites and thereby produce more precise estimates [15]. Each of the two observers interpreted a total of 4788 observation points (228 observation points per site per image type $\times$ seven sites $\times$ three image types). Having the grid point at the center, a square of 0.5 ha (about $70 \mathrm{~m} \times 70 \mathrm{~m}$ ) was created for all of the 228 grid points within each site. This cell layer was the unit of interpretation of the LULC class. This cell size was chosen to match with the minimum area of the national and FAO definitions of forest. Within these 0.5 ha cells, a systematic grid consisting of 49 squares of $2 \mathrm{~m} \times 2 \mathrm{~m}$ in size, was arranged. These small squares were used in the visual interpretation to observe the presence/absence of tree crowns, and then used for canopy cover determination. The canopy cover of a single cell of 0.5 ha was determined using the count of points that coincided with the crowns of trees divided by 49 . The images were clipped to $1 \mathrm{~km} \times 1 \mathrm{~km}$ tiles for each of the 228 points, and centered at each point to have a better overview of the surrounding land cover during the interpretation. A package was written in $\mathrm{R}$ language to develop a graphical user interface that was used to display images for each point in a completely randomized manner, and record and save the results of the image interpretation. The 0.5 -ha cell with 49 grid points was enabled to be zoomed in and displayed together with the clipped image (Figure 2). In addition, the land-cover type, time of acquisition for the selected image, and elapsed time (time from launching a location to saving results) were recorded.

A given LULC type within the 0.5 ha was determined visually based on the IPCC definitions of LULC categories [15] i.e., forest land, cropland, grassland, wetland, settlements, and other land; see the IPCC guidelines for details. The thresholds for forest land were 0.5 ha area and 20\% canopy cover in the current study. Furthermore, interpretation decisions were made following a hierarchy of rules [34] (Figure 3). The proportions of points that fell on tree crowns (if any) were determined, regardless of the LULC class types. Among the potential images for interpretation, the newest image was used. Two persons performed the interpretation, and the average of the interpretation results was used in further analyses.

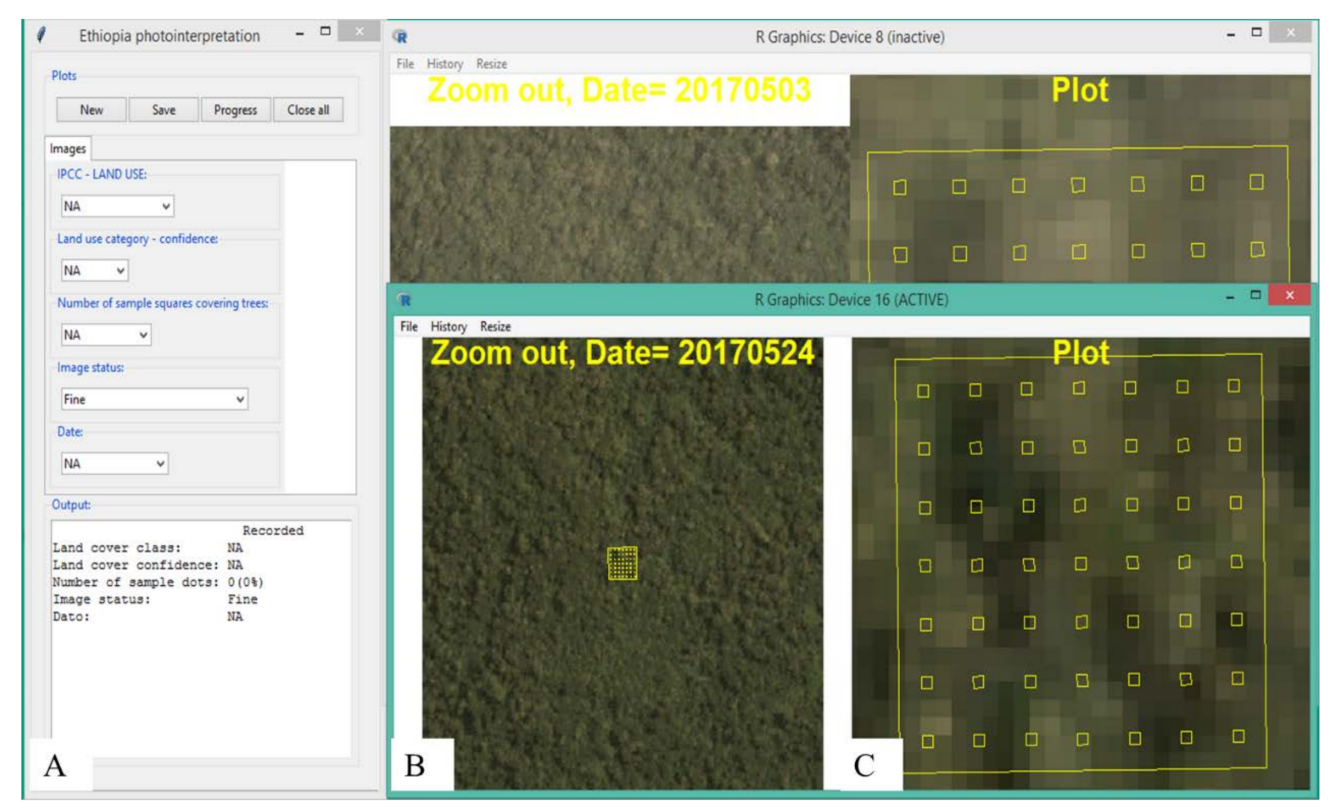

Figure 2. The graphical user interface used for visual image interpretation. (A) A window for opening new image and recording the interpreted data; (B) $1 \mathrm{~km} \times 1 \mathrm{~km}$ image with a point at the center; (C) a zoomed into 0.5 -ha cell with the 49 points ( $2 \mathrm{~m} \times 2 \mathrm{~m}$ squares). 


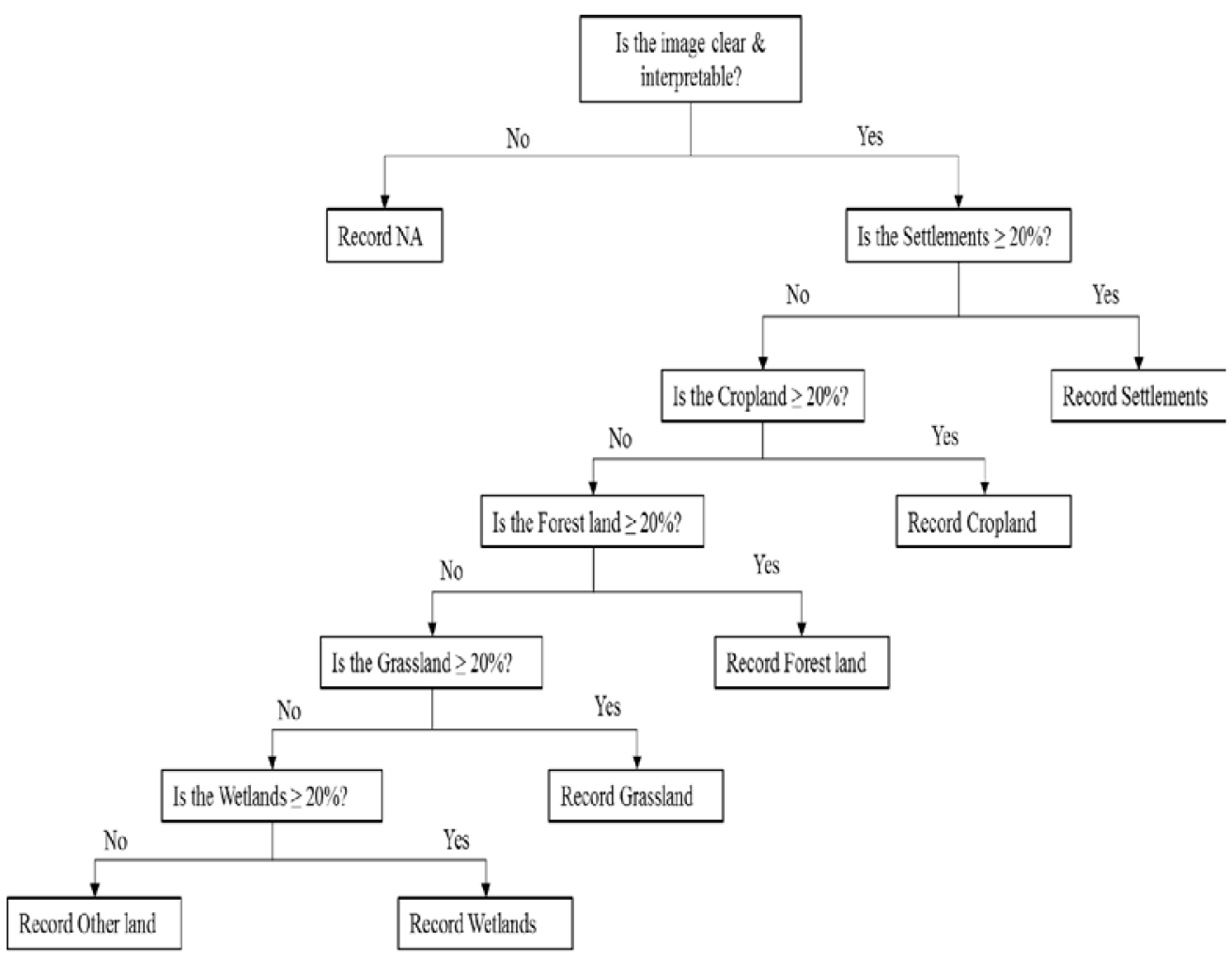

Figure 3. Decision tree based on the hierarchy of rules.

\subsection{Estimation}

Forest area estimates were computed for the three image types in all seven sites. Observation points were coded as 1 if they were forest and 0 otherwise, and then the mean forest area was estimated using the expression in Equation (1). Canopy cover estimates were also computed for the different image types in the seven respective sites, as well as each LULC class, applying the estimator in Equation (2):

$$
\hat{\bar{X}}_{i}=\frac{\sum_{j=1}^{n} x_{i j}}{n},
$$

where $\hat{X}_{i}$ is the mean forest area estimate of site $i ; x_{i j}$ is the proportion of forest area observed in site $i$ at sample point $j$; and $n$ is the number of observations in a site $i$.

$$
\hat{\bar{Y}}_{i}=\frac{\sum_{j=1}^{n} y_{i j}}{n},
$$

where $\hat{\bar{Y}}_{i}$ is the estimated mean canopy cover of site $i$; and $n$ is the number of observations.

The uncertainty of each estimate was computed using Equations (3) and (4) for forest area and canopy cover, respectively. The standard error (SE) of the mean of each estimate was computed by taking the square root of the error variance. An analysis of variance was then performed to assess the presence of significant differences among the forest area and canopy cover estimates from each image type.

$$
\widehat{\operatorname{Var}}\left(\hat{\bar{X}}_{i}\right)=\frac{\sum_{j=1}^{n}\left(x_{i j}-\hat{\bar{X}}_{i}\right)^{2}}{n(n-1)}
$$

where $\widehat{\operatorname{Var}}\left(\hat{\bar{X}}_{i}\right)$ is the estimated error variance of the mean forest area estimate of site $i$. 


$$
\widehat{\operatorname{Var}}\left(\hat{\bar{Y}}_{i}\right)=\frac{\sum_{j=1}^{n}\left(y_{i j}-\hat{\bar{Y}}_{i}\right)^{2}}{n(n-1)},
$$

where $\widehat{\operatorname{Var}}\left(\hat{\bar{Y}}_{i}\right)$ is the error variance of the mean canopy cover estimate of site $i$.

Analysis was carried out on the data that were averaged between the two observers, as given in Table 3.

Table 3. Observation results of forest and non-forest classes from the three image types.

\begin{tabular}{cccc}
\hline Observation & PlanetScope & RapidEye & Sentinel-2 \\
\hline Forest & 819 & 824 & 602 \\
Non-Forest & 774 & 772 & 947 \\
NA & 3 & 0 & 47 \\
Total & 1596 & 1596 & 1596 \\
\hline
\end{tabular}

* Not recorded due to clouds or missing imagery.

In order to assess the effects of the number of observations, bootstrap sampling was carried out for each of the forest area and canopy cover estimates of the three image types and the seven respective sites. Four different resample sizes ( $m=50,100,150$, and 200) were used in the bootstrapping with replacement, and the standard deviation of the boot statistics (Equation (5)), which is an estimate of the standard error [35], was computed and compared with the standard error of the original sample:

$$
S E_{b o o t, \bar{x}}=\sqrt{\frac{1}{m-1} \sum\left(\bar{x} *-\frac{1}{m} \sum \bar{x} *\right)^{2}}
$$

where $S E_{b o o t, \bar{x}}$ is the standard error of an estimate, and $\bar{x} *$ is the mean of each resample.

\section{Results}

\subsection{Dates and Time Elapsed for Interpretation}

There was a substantial difference between the acquisition dates of the images selected for interpretation for the different image types. For PlanetScope imagery, $85 \%$ of the images used were from May 2017, and only 2.4\% were from March and earlier. For Sentinel-2 imagery, 51\% were from May and April, and only a marginal number were from pre-2017 ( $<1 \%)$. Meanwhile, for RapidEye, none of the images interpreted was from April and May 2017, and only 23\% were acquired in 2017. However, most of the images were acquired during the dry season (December-May), except for $13 \%$ of the images from RapidEye, which were acquired in October and November. There was no identified effect of any differences in the time of acquisitions.

On average, $83 \mathrm{~s}$ were used for each location to record the LULC class and canopy coverage. The difference between RapidEye and Sentinel-2 was minor (68 s versus 73 s), while for PlanetScope, $107 \mathrm{~s}$ on average were needed to carry out the interpretation for each location. The seven sites were forming three clusters with respect to time consumption. The time consumption for the three groups were 67-75 s (sites A, F, and G), 87-89 s (sites C, D, and E) and $103 \mathrm{~s}$ (site B).

\subsection{Forest Area Estimation}

Mean forest area estimates from the three image types for all of the study sites are displayed in Figure 4. Sites B, D, and E were the three densely forested sites with estimated proportions of forest area of $0.89,0.77$, and 0.60 from PlanetScope, 0.88, 0.76, and 0.56 from RapidEye, and 0.55, 0.48 , and 0.41 from Sentinel-2, respectively. On the other hand, site F has the least forest cover, with an estimated proportion of forest area of 0.03, 0.07, and 0.05 from the PlanetScope, RapidEye, and 
Sentinel-2 images, respectively. Forest area estimates from PlanetScope and RapidEye images showed similarities consistently over the seven study sites, although there were marginal differences, where estimates from RapidEye image were smaller in most cases. The estimates from Sentinel-2 images differed from the other two image types in most of the study sites, and these differences in mean forest area were much larger and statistically significant $(p<0.01)$ for sites B, D, E, and G. However, the magnitude of the differences in mean forest area estimates decreased as the overall forest cover of the sites decreased. Thus, no significant differences were observed among the different image types for the three study sites A, C, and F, which had relatively smaller forest cover. It appears that when an area has a small proportion of forest such as sites A, C, and F, Sentinel-2 images, having relatively coarser resolution than PlanetScope and RapidEye images, would produce a reasonably comparable estimate.

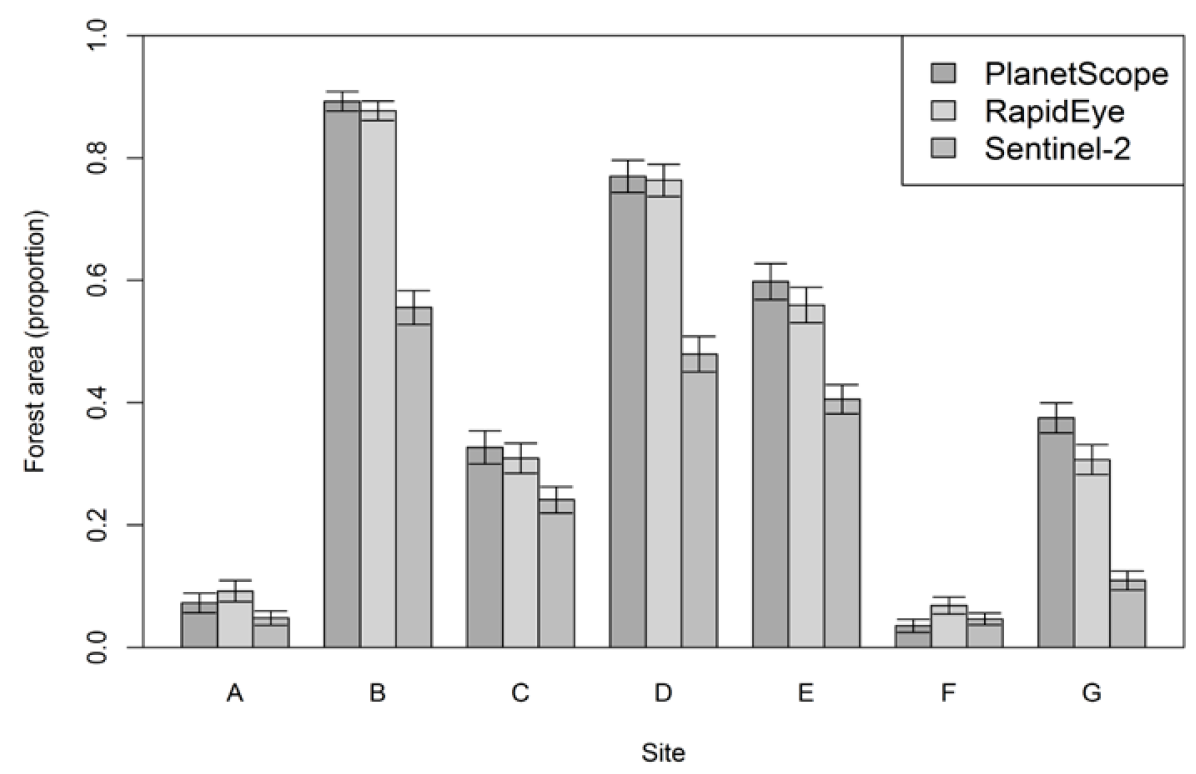

Figure 4. Forest area (proportion) estimates from PlanetScope, RapidEye, and Sentinel-2 images for each study site $(A-G)$. Error bars represent the estimated standard error of the mean.

\subsection{Canopy Cover Estimation}

Estimates of proportions of canopy cover from the three image types for all of the study sites are shown in Figure 5 and for LULC classes in Figure 6. The largest canopy cover estimate was recorded for site B as $0.59,0.56$, and 0.34 using PlanetScope, RapidEye, and Sentinel-2 images, respectively. By contrast, site F showed the smallest estimates of all of the sites with canopy cover estimates of 0.05 , 0.09 , and 0.07 from PlanetScope, RapidEye, and Sentinel-2 images. Estimates from PlanetScope and RapidEye images again appeared to be comparable, with a slightly larger difference between them than those of the forest area estimates. Nevertheless, no statistically significant difference was seen in any site between the two software packages. In sites A, C, and F, all of which had less forest cover, Sentinel-2 produced quite similar estimates to the other image types. In contrast, in sites B, D, E, and G, which had large forest cover where one also could expect large canopy cover, the estimates from Sentinel-2 significantly varied $(p<0.01)$ from the rest. This shows that the estimates from Sentinel-2 images provided smaller canopy cover values where forests tended to be denser compared to PlanetScope and RapidEye. In terms of overall performance, when taking into account the magnitude of the standard errors of canopy cover estimates of all of the sites, although the differences were not that big, PlanetScope seemed to produce a precise estimate since it on average had the smallest value, whereas RapidEye and Sentinel-2 resulted in slightly less precise estimates (Figure 7). 


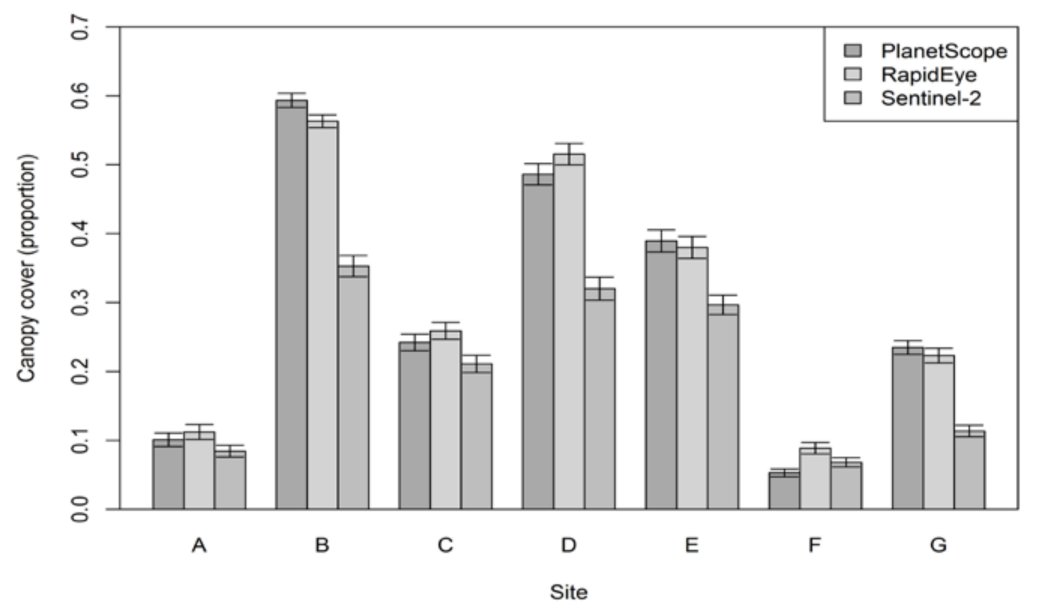

Figure 5. Canopy cover (proportion) estimates from PlanetScope, RapidEye, and Sentinel-2 images for each study site $(A-G)$. Error bars represent the estimated standard error of the mean.

When analyses of estimates of tree canopy cover were carried out for each LULC class using the three image types (Figure 6) the largest proportion of canopy cover estimate was, as expected, obtained in the Forest land category, with a magnitude of 0.57 from PlanetScope, 0.59 from RapidEye, and 0.58 from the Sentinel-2 images. According to the estimates from PlanetScope, Settlements (0.10), Cropland (0.09), and Grassland (0.08) were the second, third, and fourth LULC classes in terms of their canopy coverage. Within each LULC class, the different image types resulted in estimates that were very similar to each other except for the Settlements, Wetlands, and Other land classes. However, even in these classes, the differences were not significant in the statistical sense. It seems that if a given LULC class is a homogenous one such as Forest land, Cropland, or Grassland, then any of these images could produce reasonably comparable estimates of canopy cover. Whereas on the contrary, in heterogeneous LULC scenarios, coarser resolution images tended to either overestimate or underestimate canopy cover as compared with estimates from finer resolution images. Considering overall standard errors for each image type, it was observed that PlanetScope resulted in a smaller overall variability, showing a better precision of estimates, whereas the largest variability of estimates was seen for RapidEye (Figure 7).

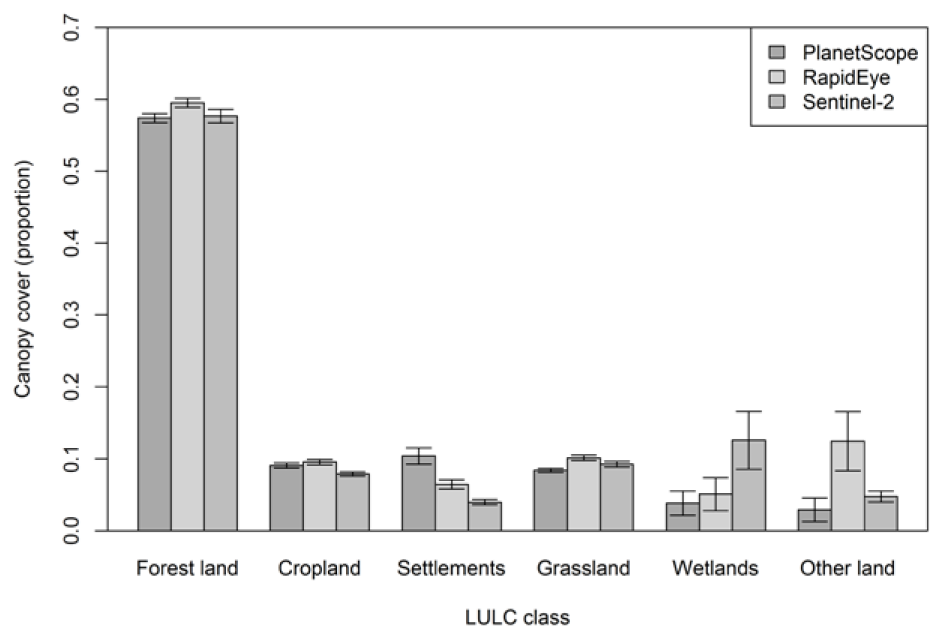

Figure 6. Canopy cover (proportion) estimates from PlanetScope, RapidEye, and Sentinel-2 images by land-use and land-cover (LULC) classes. Error bars represent the estimated standard error of the mean. 


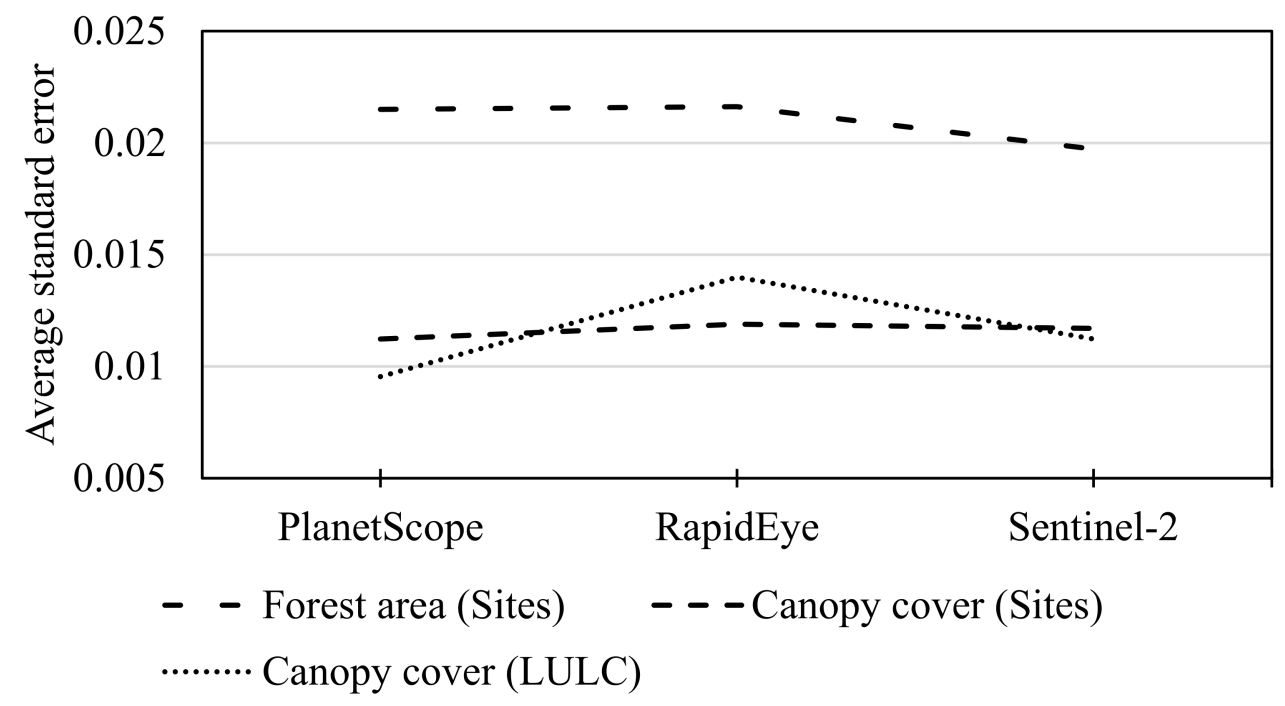

Figure 7. Average standard error for forest area and canopy cover estimates by sites as well as for canopy cover estimates by LULC classes from the three image types.

\subsection{Optimal Sample Size Determination}

The results from the bootstrapping showed increasing standard errors as the sample size decreased for both forest area and canopy cover estimates, regardless of site and image type (Figure 8). Resampling with a sample size of 200 observations resulted in estimates that were very close to the original sample size of 228 , followed by 150,100 , and 50 as the second, third, and fourth closest estimates, respectively. On average, the increase in standard error when using 200 instead of 228 sample observations was $6.7 \%, 6.5 \%$, and $4.9 \%$ for forest area and $8.7 \%, 6.0 \%$, and $4.2 \%$ for canopy cover estimates from PlanetScope, RapidEye, and Sentinel-2, respectively. Similarly, samples of 150 observations on average generated estimates with a standard error inflation of less than $24.0 \%$ for all of the image types and both forest area and canopy cover estimations. Furthermore, when the sample size was reduced to 100 observations, the standard error increased almost by $50 \%$.

The standard errors were consistently smaller for site $\mathrm{F}$ than for the rest of the study sites. In addition, the standard error values of sites $\mathrm{A}$ and $\mathrm{F}$ were entirely below the average curve, while those of sites D and $\mathrm{E}$ were constantly above the average curve for both the forest area and canopy cover estimates of the three image types (Figure 8). Reducing the sample size to only 50 observations resulted in a steeper curve and increased the standard errors by more than $100 \%$ in all of the cases. In general, considering the sample sizes, overall estimates of PlanetScope and RapidEye were found to be less sensitive to the reduction of sample size for forest area and canopy cover estimations, and the ranges of percentage increment across the sites were smaller in each respective case. Meanwhile, the Sentinel-2 estimates were highly sensitive in both cases with larger range values across the sites, regardless of having some smaller values. 


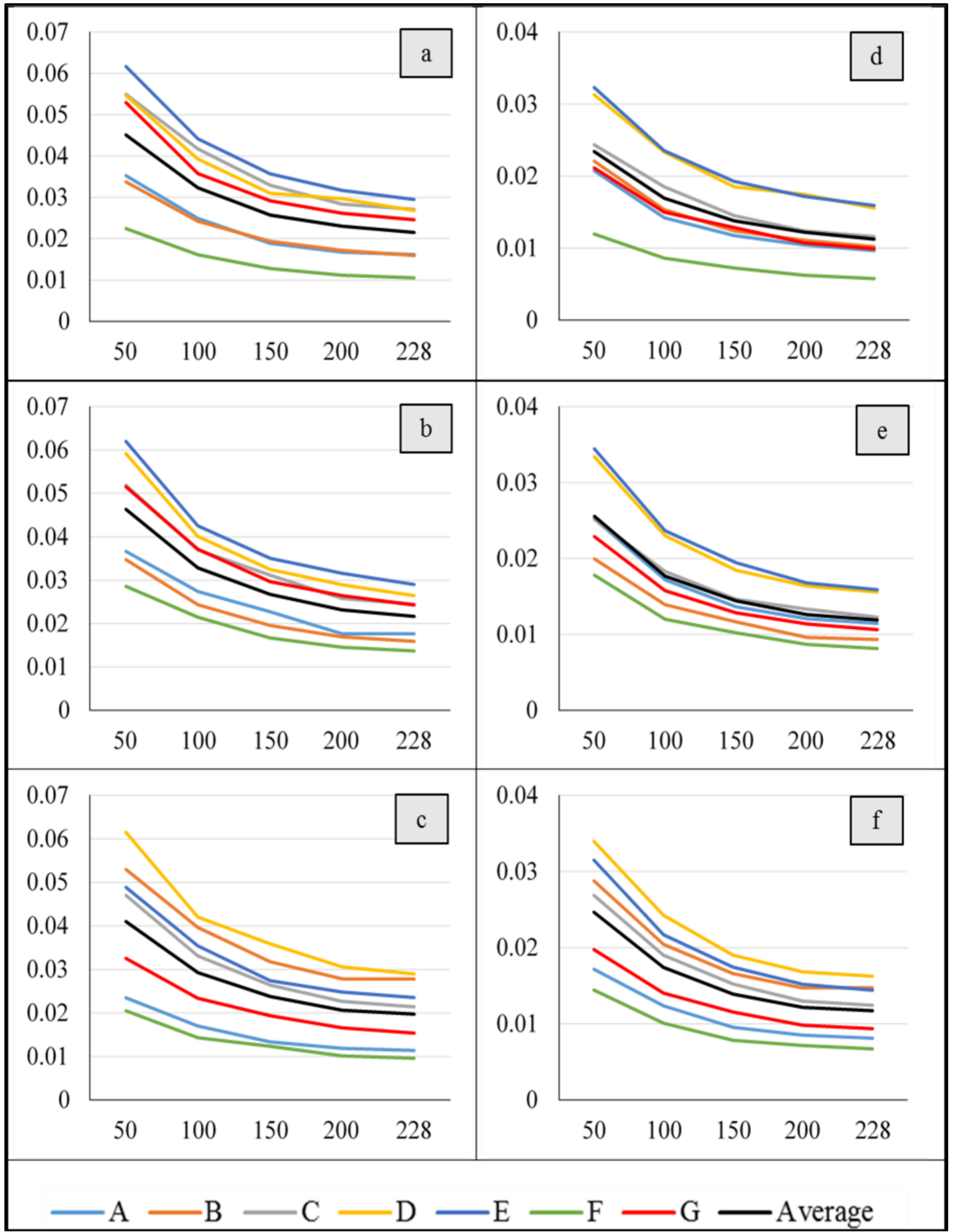

Figure 8. Standard error ( $y$-axis) for forest area and canopy cover estimates in connection with sample size ( $x$-axis). The results were determined through bootstrapping, except for 228 obtained from the original sample. $(\mathbf{a}-\mathbf{c})$ are for forest area; and $(\mathbf{d}-\mathbf{f})$ are for canopy cover estimates from PlanetScope, RapidEye, and Sentinel-2 images, respectively.

\section{Discussion}

\subsection{Visual Image Interpretation in a $R E D D+M R V$}

Visual image interpretation was adopted in this study to estimate the proportion of forest area and crown cover in seven subjectively selected sites in Ethiopia that have different forest and 
vegetation types. Satellite images of PlanetScope, RapidEye, and Sentinel-2 were examined for their performance of producing estimates of forest area and canopy cover across the variety of site conditions. In addition, the study evaluated how sample size affected the uncertainty of the estimates from different image types.

The proportion of forest cover within an area of interest can be used to estimate the area of the forest by multiplying it with the total size of the area. Such information are of paramount importance for LULC change analysis as well as the quantification of emissions and removals for REDD+ activities [23,36]. Likewise, canopy cover information is used in several forest management applications. For instance, it serves as an important ecological indicator such as for habitat, microclimate, and light condition assessment [18], and it is used as a criterion in forest definitions [17].

In the current study, it was possible to record data representing $390 \mathrm{~km}^{2}$ per hour on average. Meanwhile, for field surveys, only moving to a field plot representing $9 \mathrm{~km}^{2}$ could be difficult within the same amount of time. Thus, the efficiency of visual interpretation is the major advantage. However, a disadvantage is the amount of subjectivity that is allowed in the interpretation. In this study, the average interpretation between two interpreters was used. However, if multiple interpreters are available, the difference between them could be calculated and thus calibrated for. Hence, multiple interpreters can mitigate systematic errors occurring due to individual decisions. In addition, it is problematic that the interpreted value could also have errors when trained and experienced interpreters are carrying out the work. Experience form Tanzania showed that tree cover and the amount of woody biomass is not necessarily a good indicator of land-use or land-cover classification in field [37]. Thus, a major confine of the current study is that we did not have any ground-measured value. However, indicating that differences between the imagery exist is important. A natural assumption is that higher resolution imageries provide a more accurate interpretation.

In this study, design-based estimates were the focus, and only the interpretations for the observation points were used to create estimates. The next step for implementing REDD+ MRV could be to include complete cover information e.g., from PlanetScope, RapidEye, or Sentinel, and combine the complete cover information with the interpretations making a wall-to-wall map that can be used in model-assisted estimation $[37,38]$. This will be a natural extension of the current study, as capacity building are taking place in the REDD+ countries.

\subsection{Factors Influencing Estimates}

Proportions of forest area estimated using PlanetScope and RapidEye images were very similar across the seven sites, regardless of their differences in spatial resolution. On the other hand, estimates from Sentinel-2 images for most of the sites differed significantly from those of both PlanetScope and RapidEye images. Exactly the same pattern of similarities and differences occurred as well for canopy cover estimates. It seemed that PlanetScope and RapidEye estimates were robust and capable of producing reliable results in different biomes with different forest types and magnitudes of forest coverage. However, the performance of Sentinel-2 images seemed to be dependent on the magnitude of forest cover. It produced similar estimates to those of PlanetScope and RapidEye for areas with less forest cover, and varied as the forest cover of the area increased. Each land-cover category has its own property that needs to be considered when selecting methods, including the images to be used for land-cover classification and mapping [39]. Accordingly, the discrepancy among estimates from these image types is perhaps due to a number of factors, one of which is the differences in the resolution of the images. Draksler [40] investigated the effect of satellite image resolution and minimum mapping unit on the accuracy of forest cover mapping in two different sites using RapidEye, Sentinel-2, and Landsat-8, and reported a declining trend in overall accuracy as the resolution got coarser. A similar trend was reported by Churches et al. [41], who compared forest cover estimates of Haiti using different satellite images.

Another factor contributing to the differences could be missing data, which will reduce the number of observations and hence affect the quality of estimates [42]. Most of the missing data during 
image interpretation (NAs) were recorded for Sentinel-2 images (Table 3). Out of the total NAs in Sentinel-2, more than $70 \%$ were in sites B and D. These are the sites that are known to have denser forest cover and be accompanied by the presence of heavy cloud cover during most of the year. Therefore, its relatively coarser resolution coupled with the cloud cover might have affected the interpretation result, since it failed to sufficiently capture the existing variability within the study sites. The revisit frequency also directly influences the availability at cloudy locations. The frequent revisits of PlanetScope is highly favorable for REDD+ MRV, since $85 \%$ of the images used for the interpretations were acquired within a time period of one month, May 2017, while for RapidEye and Sentinel-2, a maximum of 34\% and $40 \%$ of the images originated from one single month, respectively.

The majority of the images used for interpretation was acquired during the dry season. One reason for this is that cloud coverage is smaller in this season compared with the rainy season. It is likely that the phenology of the trees and other vegetation influences the interpretation. A tree crown with more leaves could potentially lead to a larger interpreted crown cover compared with when the tree has less or no leaves. The design of this study did not provide data to analyze the effect of seasonality in a statistical sense.

Satellite imagery used for the visual interpretation of forest area and canopy cover should be carefully selected. For low-density forest areas, say, somewhere below 30\% canopy cover, Sentinel-2 images may be safely used, whereas for denser forest areas, higher resolution images such as PlanetScope and RapidEye should be considered. Of course, the choice may depend on the purpose of the study and available resources. To reduce costs, sampling instead of large-scale wall-to-wall observation could be used $[43,44]$. The method used in this study is such an alternative to obtain reliable estimates at a lower cost of image procurement, especially for dense forest areas where low-resolution images have deficiencies, and the quality of information pays off.

\subsection{Sample Size}

When resources allocated for data collection are limited, it is important also to apply appropriate sampling designs and use adequate sampling intensities $[45,46]$. Hence, it would be necessary to look for and determine optimal sample sizes that will result in a precise estimate with the possible minimum resource [45]. The bootstrapping technique allowed us to repeatedly sample from a given set of observations and assess the uncertainty of an estimate under certain circumstances, such as for example with different sample sizes, as in our case. As indicated in Figure 8, the precision of the estimates is sensitive to changes in the number of observations in the sample. The sensitivity also differs depending on the parameter of interest to be estimated as well as the types of images to be used. Hence, depending on the purpose of the study, the available resources, and the precisions that are required, one may decide on the number of observations accordingly. From the analysis of sample size in the current study, it seems possible to reduce the sample size slightly without substantially affecting the obtained accuracy. Perhaps a sample plot spacing of $3.5 \mathrm{~km}$ or $4 \mathrm{~km}$ between sample locations could have been considered.

\section{Conclusions}

Forest area and canopy cover estimates are among the most essential information in any forest management practice. One of the approaches to derive such information is through visual image interpretation techniques using satellite images. The technique is particularly quick, less costly, and helpful when the technical capacities to use digital image classification and mapping are limited. In this study, visual image interpretation was applied, and the use of PlanetScope, RapidEye, and Sentinel-2 satellite images for forest area and canopy cover estimation was evaluated. PlanetScope and RapidEye images produced similar estimates for all of the study sites and all of the LULC classes. Sentinel-2 image estimates varied significantly from the two other types of images in study sites with relatively denser forest cover, but resulted in similar estimates in sites with less dense forests. In visual image interpretation practices, very high-resolution images should be given priority. The choice of 
image type can be influenced by the condition of the forest on the ground as well as the costs of the images. In case of using expensive and very high-resolution images, a sampling approach could reduce the overall costs compared to wall-to-wall acquisitions. Furthermore, the precision of the estimate is dependent on the sample size. Therefore, by taking the purpose of the assessment as well as the available resources into account, one should aim for sample sizes that balance the inventory costs and the required precision of an estimate.

Author Contributions: Z.A. and H.T. performed the experiments, analyzed the data and wrote the paper; H.O.Ø. conceived and designed the experiments, supervised all the research work that led to this paper and reviewed the manuscript; T.G. supervised the research work that led to this paper and reviewed the manuscript; I.B. reviewed the manuscript; E.N. provided inputs to the experiments and reviewed the manuscript.

Funding: The first and second authors of the study are funded as a Ph.D. student by the Norwegian Government through support of the project "National MRV capacity Building towards Climate Resilient Development in Ethiopia".

Acknowledgments: Special thanks should go to the Norwegian University of Life Sciences and Wondo Genet College of Forestry and Natural Resources (Hawassa University). The authors would also like to thank the Planet Company for allowing to freely download and use PlanetScope and RapidEye images in this study.

Conflicts of Interest: The founding sponsors had no role in the design of the study; in the collection, analyses, or interpretation of data; in the writing of the manuscript, and in the decision to publish the results.

\section{References}

1. Dudley, N.; Stolton, S. Running Pure: The Importance of Forest Protected Areas to Drinking Water. World Bank/WWF Alliance for Forest Conservation and Sustainable Use, 2003. Available online: http: //d2ouvy59p0dg6k.cloudfront.net/downloads/runningpurereport.pdf (accessed 16 November 2017).

2. McMahon, P. A Burning Issue: Tropical Forests and the Health of Global Ecosystems. In Challenges and Opportunities for the World's Forests in the 21st Century; Fenning, T., Ed.; Springer: Dordrecht, The Netherlands, 2014; pp. 23-35.

3. Le Quéré, C.; Raupach, M.R.; Canadell, J.G.; Marland, G.; Bopp, L.; Ciais, P.; Conway, T.J.; Doney, S.C.; Feely, R.A.; Foster, P.; et al. Trends in the sources and sinks of carbon dioxide. Nat. Geosci. 2009, 2, 831-836.

4. Canadell, J.G.; Le Quéré, C.; Raupach, M.R.; Field, C.B.; Buitenhuis, E.T.; Ciais, P.; Conway, T.J.; Gillett, N.P.; Houghton, R.A.; Marland, G. Contributions to accelerating atmospheric $\mathrm{CO}_{2}$ growth from economic activity, carbon intensity, and efficiency of natural sinks. Proc. Natl. Acad. Sci. USA 2007, 104, 18866-18870. [CrossRef] [PubMed]

5. Pan, Y.; Birdsey, R.A.; Fang, J.; Houghton, R.; Kauppi, P.E.; Kurz, W.A.; Phillips, O.L.; Shvidenko, A.; Lewis, S.L.; Canadell, J.G.; et al. A large and persistent carbon sink in the world's forests. Science 2011, 333, 988-993. [CrossRef] [PubMed]

6. Baccini, A.; Friedl, M.A.; Woodcock, C.E.; Warbington, R. Forest biomass estimation over regional scales using multisource data. Geophys. Res. Lett. 2004, 31, L10501. [CrossRef]

7. Kim, D.-H.; Sexton, J.O.; Townshend, J.R. Accelerated Deforestation in the Humid Tropics from the 1990s to the 2000s. Geophys. Res. Lett. 2015. [CrossRef] [PubMed]

8. Van der Werf, G.R.; Morton, D.C.; DeFries, R.S.; Olivier, J.G.J.; Kasibhatla, P.S.; Jackson, R.B.; Collatz, G.J.; Randerson, J.T. $\mathrm{CO}_{2}$ emissions from forest loss. Nat. Geosci. 2009, 2, 737-738. [CrossRef]

9. Noriko, H.; Martin, H.; Veronique De, S.; Ruth, S.D.F; Maria, B.; Louis, V.; Arild, A.; Erika, R. An assessment of deforestation and forest degradation drivers in developing countries. Environ. Res. Lett. 2012, 7, 044009. [CrossRef]

10. Pohjonen, V.; Pukkala, T. Eucalyptus globulus in Ethiopian forestry. For. Ecol. Manag. 1990, 36, 19-31. [CrossRef]

11. Bishaw, B. Deforestation and Land Degradation in the Ethiopian Highlands: A Strategy for Physical Recovery. Northeast Afr. Stud. 2001, 8, 7-25. [CrossRef]

12. McCann, J.C. The Plow and the Forest: Narratives of Deforestation in Ethiopia, 1840-1992. Environ. Hist. 1997, 2, 138-159. [CrossRef] 
13. Kindu, M.; Schneider, T.; Teketay, D.; Knoke, T. Land Use/Land Cover Change Analysis Using Object-Based Classification Approach in Munessa-Shashemene Landscape of the Ethiopian Highlands. Remote Sens. 2013, 5, 2411-2435. [CrossRef]

14. Hailemariam, S.N.; Soromessa, T.; Teketay, D. Land Use and Land Cover Change in the Bale Mountain Eco-Region of Ethiopia during 1985 to 2015. Land 2016, 5, 41. [CrossRef]

15. Penman, J.; Gytarsky, M.; Hiraishi, T.; Krug, T.; Kruger, D.; Pipatti, R.; Buendia, L.; Miwa, K.; Ngara, T.; Tanabe, K.; et al. Good Practice Guidance for Land Use, Land-Use Change and Forestry; IPCC: Geneva, Switzerland, 2003.

16. Chazdon, R.L.; Brancalion, P.H.S.; Laestadius, L.; Bennett-Curry, A.; Buckingham, K.; Kumar, C.; Moll-Rocek, J.; Vieira, I.C.L.G.E.; Wilson, S.J. When is a forest a forest? Forest concepts and definitions in the era of forest and landscape restoration. Ambio 2016, 45, 538-550. [CrossRef] [PubMed]

17. FAO. Global Forest Resources Assessment 2000; Forestry Paper No. 140; UN Food and Agricultural Organization: Rome, Italy, 2001.

18. Jennings, S.B.; Brown, N.D.; Sheil, D. Assessing forest canopies and understorey illumination: Canopy closure, canopy cover and other measures. Forestry 1999, 72, 59-73. [CrossRef]

19. Gschwantner, T.; Schadauer, K.; Vidal, C.; Lanz, A.; Tomppo, E.; di Cosmo, L.; Robert, N.; Duursma, D.E.; Lawrence, M. Common Tree Definitions for National Forest Inventories in Europe. Silva Fenn. 2009, 43, 303-321. [CrossRef]

20. Korhonen, L.; Korhonen, K.T.; Rautiainen, M.; Stenberg, P. Estimation of forest canopy cover: A comparison of field measurement techniques. Silva Fenn. 2006, 40, 577-588. [CrossRef]

21. Mbow, C.; Skole, D.; Dieng, M.; Justice, C.; Kwesha, D.; Mane, L.; El Gamri, M.; Von Vordzogbe, V.; Virji, H. Challenges and Prospects for REDD+ in Africa: Desk Review of REDD+ Implementation in Africa; Global Land Project Reports; GLP International Project Office: Copenhagen, Denmark, 2012; Volume 5.

22. Herold, M.; Skutsch, M. Monitoring, reporting and verification for national REDD + programmes: Two proposals. Environ. Res. Lett. 2011, 6, 014002. [CrossRef]

23. IPCC. 2006 IPCC Guidelines for National Greenhouse Gas Inventories; IGES: Berlin, Germay, 2006.

24. IPCC. Land Use, Land Use Change, and Forestry; Cambridge University Press: Cambridge, UK, 2000.

25. Bey, A.; Díaz, A.S.-P.; Maniatis, D.; Marchi, G.; Mollicone, D.; Ricci, S.; Bastin, J.-F.O.; Moore, R.; Federici, S.; Rezende, M.; et al. Collect Earth: Land Use and Land Cover Assessment through Augmented Visual Interpretation. Remote Sens. 2016, 8, 807. [CrossRef]

26. Clark, M.L.; Aide, T.M. Virtual Interpretation of Earth Web-Interface Tool (VIEW-IT) for Collecting Land-Use/Land-Cover Reference Data. Remote Sens. 2011, 3, 601-620. [CrossRef]

27. MEFCC. Ethiopia's Forest Reference Level Submittssion to the UNFCCC; Ministry of Environment, Forestry and Climate Change: Addis Ababa, Ethiopia, 2017.

28. Fritz, S.; McCallum, I.; Schill, C.; Perger, C.; See, L.; Schepaschenko, D.; van der Velde, M.; Kraxner, F.; Obersteiner, M. Geo-Wiki: An online platform for improving global land cover. Environ. Model. Softw. 2012, 31, 110-123. [CrossRef]

29. Fritz, S.; McCallum, I.; Schill, C.; Perger, C.; Grillmayer, R.; Achard, F.; Kraxner, F.; Obersteiner, M. Geo-Wiki.Org: The Use of Crowdsourcing to Improve Global Land Cover. Remote Sens. 2009, 1, 345-354. [CrossRef]

30. Sannier, C.; McRoberts, R.E.; Fichet, L.-V.; Makaga, E.M.K. Using the regression estimator with Landsat data to estimate proportion forest cover and net proportion deforestation in Gabon. Remote Sens. Environ. 2014, 151, 138-148. [CrossRef]

31. Potapov, P.V.; Dempewolf, J.; Talero, Y.; Hansen, M.C.; Stehman, S.V.; Vargas, C.; Rojas, E.J.; Castillo, D.; Mendoza, E.; Calderón, A.; et al. National satellite-based humid tropical forest change assessment in Peru in support of REDD+ implementation. Environ. Res. Lett. 2014, 9, 124012. [CrossRef]

32. Ib, F.; Sebsebe, D.; Breugel, P.V. Atlas of the Potential Vegetation of Ethiopia; The Royal Danish Academy of Science and Letters: Copenhagen, Denmark, 2010; Volume 58.

33. Egziabher, T.B.G. Diversity of Ethiopian flora. In Plant Genetic Resources of Ethiopia; Engles, J., Hawkes, J.G., Worede, M., Eds.; Cambridge University Press: Cambridge, UK, 1991; pp. 75-81.

34. Martínez, S.; Mollicone, D. From Land Cover to Land Use: A Methodology to Assess Land Use from Remote Sensing Data. Remote Sens. 2012, 4, 1024-1045. [CrossRef] 
35. Hesterberg, T.; Moore, D.S.; Monaghan, S.; Clipson, A.; Epstein, R. Bootstrap methods and permutation tests. In Introduction to the Practice of Statistics; W.H. Freeman \& Company: New York, NY, USA, 2003.

36. Köhl, M.; Magnussen, S.; Marchetti, M. Sampling Methods, Remote Sensing and GIS Multiresource Forest Inventory; Springer: Berlin/Heidelberg, Germany, 2006.

37. Næsset, E.; Ørka, H.O.; Solberg, S.; Bollandsås, O.M.; Hansen, E.H.; Mauya, E.; Zahabu, E.; Malimbwi, R.; Chamuya, N.; Olsson, H.; et al. Mapping and estimating forest area and aboveground biomass in miombo woodlands in Tanzania using data from airborne laser scanning, TanDEM-X, RapidEye, and global forest maps: A comparison of estimated precision. Remote Sens. Environ. 2016, 175, 282-300. [CrossRef]

38. McRoberts, R.E. Probability- and model-based approaches to inference for proportion forest using satellite imagery as ancillary data. Remote Sens. Environ. 2010, 114, 1017-1025. [CrossRef]

39. King, R.B. Land cover mapping principles: A return to interpretation fundamentals. Int. J. Remote Sens. 2002, 23, 3525-3545. [CrossRef]

40. Draksler, A. The Effect of Satellite Image Resolution and Minimum Mapping Unit on the Accuracy of Forest Cover Maps; Technische Universität München: Munich, Germany, 2017.

41. Churches, C.E.; Wampler, P.J.; Sun, W.; Smith, A.J. Evaluation of forest cover estimates for Haiti using supervised classification of Landsat data. Int. J. Appl. Earth Obs. Geoinf. 2014, 30, 203-216. [CrossRef]

42. Lohr, S. Sampling: Design and Analysis; Nelson Education: Scarborough, ON, Canada, 2009.

43. Böttcher, H.; Eisbrenner, K.; Fritz, S.; Kindermann, G.; Kraxner, F.; McCallum, I.; Obersteiner, M. An assessment of monitoring requirements and costs of 'Reduced Emissions from Deforestation and Degradation'. Carbon Balanc. Manag. 2009, 4, 14. [CrossRef] [PubMed]

44. Falkowski, M.J.; Wulder, M.A.; White, J.C.; Gillis, M.D. Supporting large-area, sample-based forest inventories with very high spatial resolution satellite imagery. Prog. Phys. Geogr. 2009, 33, 403-423. [CrossRef]

45. Jayaraman, K. A Statistical Manual for Forestry Research. FORSPA, 2000. Available online: http://www.fao. org/3/a-x6831e.pdf (accessed on 10 November 2017).

46. Lenth, R.V. Some Practical Guidelines for Effective Sample Size Determination. Am. Stat. 2001, 55, 187-193. [CrossRef] 